\title{
Who were cartographers of manuscript topographic maps in the Enlightenment?
}

\author{
Beata Medynska-Gulij \\ Department of Cartography and Geomatics, Adam Mickiewicz University, Poznan, Poland \\ email author:bmg@amu.edu.pl,
}

Keywords: cartographer in the Enlightenment, manuscript maps, watermedia, European topographic works of art,

The most difficult challenge is to provide the name of the cartographer, i.e. the author of graphic picture of topography with the use of watermedia on paper, for each important European topographic work. Even though we know the names of chiefs of survey and the most important engineers in field mapping teams, it is not possible to precisely describe their role in creating graphic style for fair copy. The aim of this study was to identify several types of design authorship of manuscript topographic maps in the Enlightenment.

Wrede's map of Silesia was developed under King Frederick II's supervision, who was himself theoretically and practically competent in map making. The mapping and the resulting protraction copy were made by Wrede and his team, but the draughtsmen were probably coordinated by Oelsnitz, head of the Potsdam drawing room. Such a hierarchical production structure, might also be recognized in the map of Norway developed by order of Huth - the Staatsminister and mathematician - who delegated the coordination of surveying and drawing activities to Staffeldt. In fact, the men responsible for the original map were cartographer Stabell and other engineers. A similar solution would explain the map of the Electorate of Hanover, produced by Hogrewe and his subordinate engineers, formally supervised by du Plat, but with the personal involvement of King George III in the decisions over segment division and cartographic content.

Institutional authorship, or maps produced by the head of a specific drawing room and his subordinate draughtsmen. The map of England, attributed to Gardner and the personnel of the Tower of London drawing room, was developed according to this system. Authorship in tandem: those engineers who performed field surveys and sketches, and later produced fair copies (e.g. Roy and Sandby's map of Scotland) - the former drew topographic objects and the latter was the sole author of landform painting; Avico and Carello (map of Susa Valley) - both put their ink signatures on the map, independent of the cartouche content.

Collective authorship where the maps were produced by draughtsmen associated with particular drawing rooms or employed to draw maps according to the protracted copies supplied. The former included, for instance, the case of the map of NE France with Lorraine (from Naudin's atelier) or the over 3,000 map segments (map of the Habsburg Dominion) developed by officers in Vienna. A further example would be the map of Austrian Netherlands, most probably involving draughtsmen educated in France.

The comparison of maps with the actual topographic situation in the countryside, also made us realize that the perception and cartographic work of various groups of map-making officers in similar cultural and surveying conditions, but in different topographic situations, might be interpreted as elements in a broader phenomenon of the understanding of space in the Enlightenment. The use of water-based media allowed for the representation of lands throughout Europe. No other technique offered map makers and artists an opportunity to reflect landscape so realistically. It is, no wonder, then, that it strongly affected the development of modern principles for cartographic design, even being translated through into the engraving and lithographic world of print. The map-making initiatives conducted in the Enlightenment were distinctive, helping define an age and a new emerging 
Europe. In these manuscript maps, we can see how eighteenth-century European contemporaries helped develop conventions - in the use of line, color, perspective, tone and topographic form - that shaped how their world was seen: on maps, in art, in the political imagination. 